\title{
PENGARUH GAYA KEPEMIMPINAN DAN DISIPLIN KERJA TERHADAP KINERJA KARYAWAN RUMAH 187 SAKIT TAMAN HARAPAN BARU BEKASI
}

\author{
Ratna Indriyani ${ }^{1}$; Rini Wijayaningsih²; Soehardi ${ }^{3}$ \\ Fakultas Ekonomi dan Bisnis Universitas Bhayangkara Jakarta Raya ${ }^{1,2,3}$
}

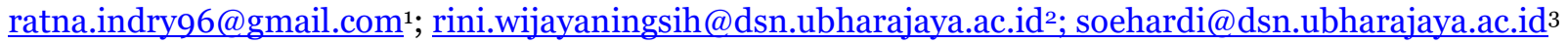

\begin{abstract}
ABSTRAK
Keberhasilan mencapai tujuan tergantung pada pemilihan tujuan yang akan dicapai dengan cara menggunakan sumber daya untuk mencapai tujuan organisasi sesuai dengan apa yang diharapkan. Penelitian ini ingin menguji kembali beberapa variable yang mempengaruhi kinerja karyawan. Metode penelitian ini menggunakan regresi linier berganda. Penelitian ini bertujuan untuk menjawab pengaruh gaya kepemimpinan dan disiplin kerja terhadap kinerja karyawan. Penelitian ini menggunakan data penyebaran kuesioner ke 105 responden. Teknik pengambilan sampel menggunakan purposive sampling dan diolah menggunakan alat statistic SPSS 22. Hasil uji parsial baik variabel gaya kepemimpinan maupun disiplin kerja berpengaruh terhadap kinerja karyawan, dan secara simultan variabel gaya kepemimpinan maupun disiplin kerja berpengaruh terhadap kinerja karyawan gaya kepemimpinan dan disiplin kerja secara bersama-sama berpengaruh terhadap kinerja karyawan.
\end{abstract}

Kata Kunci: Gaya Kepemimpinan, Disiplin Kerja dan Kinerja Karyawan

Abstract

Success in achieving goals depends on the selection of goals to be achieved by using resources to achieve organizational goals in accordance with what is expected. This study wants to re-examine some of the variables that affect employee performance. This research method uses multiple linear regression. This study aims to answer the influence of leadership style and work discipline on employee performance. This study uses questionnaire data to 105 respondents. The sampling technique used purposive sampling and processed using SPSS 22 statistical tools. The partial test results, both leadership style and work discipline variables have an effect on employee performance, and simultaneously the variables of leadership style and work discipline have an effect on employee performance. equal effect on employee performance.

Keywords: Leadership Style, Work Discipline and Employee Performance

Diterima: 30 Maret 2021; Direvisi: 6 April 2021; Diterbitkan: 20 April 2021

\section{PENDAHULUAN}

Sumber Daya manusia (SDM) tentunya mempunyai peran yang sangat penting seperti yang diketahui bahwa kinerja perusahaan dipengaruhi dengan kualitas sumber daya manusianya. Kinerja yang baik merupakan hal yang tentunya diinginkan pencapaiannya oleh setiap perusahaan. Maka dari itu dalam mengelola sumber daya manusia diperlukan arahan untuk menjadi penentu jalannya pelaksanaan bagi kalangsungan perusahaan. Untuk dapat tercapainya suatu 
kinerja yang diinginkan, tentu dibutuhkan pemimpin yang mempunyai potensi untuk dapat mengarahkan karyawannya. Perusahaan merasa diuntungkan jika karyawannya dapat mencapai hasil yang optimal dalam mengerjakan tugas yang diberikan oleh pimpinan.

Hal pertama yang mempengaruhi kinerja karyawan adalah kepemimpinan. Menurut (Fahmi, 2013) bahwa kepemimpinan memiliki pengaruh besar dalam mendorong peningkatan kinerja karyawannya. Sebagai pemimpin tentunya dapat mempengaruhi karyawannya dengan proses organisasi yang sesuai dengan kebutuhan, baik itu kebutuhan individu, kelompok maupun kebutuhan organisasi.

Untuk dapat menciptakan organisasi yang memiliki daya saing tinggi maka diperlukan orang-orang yang memiliki gaya kepemimpinan yang baik untuk setiap perubahan yang terjadi di organisasi. Gaya kepemimpinan merupakan suatu cara yang dapat digunakan oleh pemimpin untuk dapat mempengaruhi perilaku bawahannya.

Selain gaya kepemimpinan yang berpengaruh terhadap kinerja karyawan, tentunya disiplin kerja juga mempengaruhinya. Kedisiplinan dapat dikatakan fungsi manajemen yang terpenting bagi perusahaan untuk mencapai hasil yang optimal. Tentunya jika semakin baik kedisiplinan karyawan, semakin tinggi juga prestasi kerja yang dapat dicapai. Menurut (Sinambela 2016) disiplin juga bermanfaat untuk mendidik pegawai dalam mematuhi dan mentaati peraturan, prosedur, serta kebijakan yang ada sehingga menghasilkan kinerja yang baik.

Selain itu masih terdapat kurangnya rasa tanggung jawab karyawan dalam pelaksanaan tugas, dan karyawan atau pimpinan tidak menggunakan seragam sesuai yang telah ditetapkan oleh pihak rumah sakit.

Untuk dapat meningkatkan disiplin kerja yang baik tentu merupakan suatu hal yang tidak mudah. Namun untuk mengatasi hal tersebut sebagai pemimpin dapat memberikan contoh dan arahan kepada karyawannya dengan menjelaskan peraturan-peraturan yang terdapat pada perusahaan.

Perusahaan yang baik tentunya memerlukan karyawan yang memiliki kinerja yang tinggi untuk menghadapi tantangan yang ada pada lingkungan perusahaan yang semakin kompetitif dalam mencapai tujuan perusahaan yang diinginkan. Menurut (Rivai \& Sagala, 2010) kinerja merupakan perilaku nyata yang ditampilkan setiap orang sebagai prestasi kerja yang dihasilkan oleh karyawan sesuai dengan perannya dalam perusahaan. Kinerja karyawan dalam waktu tertentu perlu adanya evaluasi untuk dapat tercapai dalam melaksanakan tugas-tugas yang telah diserahkan pemimpin kepada bawahannya dengan waktu yang telah ditentukan.

\section{LANDASAN TEORI}

\section{Gaya Kepemimpinan}

Gaya kepemimpinan merupakan suatu cara yang dilakukan oleh seorang pemimpin untuk dapat mempengaruhi perilaku orang lain.Dari pola tingkah laku yang dibuat oleh pemimpin diharapkan dapat menjabarkan tujuan organisasi agar tercapainya tujuan bersama.

Menurut pendapat (Soekarso, 2010) gaya kepemimpinan adalah perilaku atau tindakan seorang pemimpin dalam 
melaksanakan tugas-tugas pekerjaan manajerial.

Sedangkan (Hapid \& Sunarwan, 2014) berpendapat bahwa gaya kepemimpinan ialah usaha-usaha pemimpin untuk mengelola, memotivasi, dan mengkategorikan keseluruhan elemen perusahaan untuk mencapai tujuannya.

Menurut (Sopiah,2012) ada berbagai macam jenis kepemimpinan, antara lain sebagai berikut:

1. Kepemimpinan Transaksional

Model kepemimpinan ini berfokus pada transaksi antar pribadi, antara manajemen dengan karyawan.

2. Kepemimpinan Karismatik

Kepemimpinan ini menekankan perilaku pemimpin yang simbolis.

3. Kepemimpinan Visioner

Kepemimpinan ini merupakan kemampuan untuk menciptakan dan mengartikulasikan suatu visi yang realistis, dapat dipercaya, atraktif dengan masa depan bagi suatu organisasi atau unit organisasi yang terus tumbuh dan terus meningkat.

4. Kepemimpin Tim

Menjadi pemimpin efektif harus mempelajari keterampilan seperti kesabaran untuk membagi informasi, percaya kepada orang lain, menghentikan otoritas dan memahami kapan harus melakukan intervensi.

Menurut (Ardana, Mujiati dan Utama 2012) disiplin kerja adalah suatu sikap menghormati, menghargai, patuh, dan taat terhadap peraturan-peraturan yang berlaku, baik yang tertulis maupun tidak tertulis serta sanggup menjalankannya dan tidak mengelak untuk menerima sanksisanksinya.

Menurut (Sinambela, 2016) disiplin juga bermanfaat untuk mendidik pegawai dalam mematuhi dan mentaati peraturan, prosedur, serta kebijakan yang ada sehingga menghasilkan kinerja yang baik.

Sedangkan (Hasibuan, 2013) mengatakan bahwa seorang karyawan dikatakan memiliki disiplin kerja yang tinggi apabila memenuhi kriteria berdasarkan sikap, norma, dan tanggungjawab.

Menurut (Sutrisno, 2014) mengemukakan bahwa faktor-faktor yang mempengaruhi disiplin kerja adalah:

1. Pemberian kompensasi;

2. Keteladanan pimpinan dalam perusahaan;

3. Aturan pasti yang dijadikan pegangan;

4. Keberanian pimpinan dalam mengambil tindakan;

5. Pengawasan pimpinan;

6. Perhatian kepada karyawan dan;

7. Kebiasaan-kebiasaan pendukung disiplin.

\section{Kinerja Karyawan}

Kinerja merupakan kesuksesan seseorang dalam melaksanakan pekerjaannya. Kinerja yang baik dapat dilihat dari prosedur dan mengikuti tata cara sesuai standar yang telah ditetapkan. Menurut (Sedarmayanti, 2010), kinerja merupakan hasil kerja seseorang, dimana keseluruhan hasil tersebut dapat dibuktikan secara konkrit dan dapat diukur.

Menurut (Prawirosentono, 2012) menyebutkan kinerja, atau performance adalah hasil kerja yang dapat dicapai oleh seorang atau sekelompok orang dalam suatu organisasi, sesuai dengan tanggung jawab dan wewenang masing-masing dalam upaya mencapai tujuan organisasi.

Sedangkan (Marwansyah, 2012) mengatakan bahwa Kinerja adalah pencapaian/prestasi seseorang berkenaan 
dengan tugas-tugas yang dibebankan kepadanya.Kinerja juga pula dipandang sebagai perpaduan dari hasil kerja (apa yang harus dicapai seseorang) dan kompetensi (bagaimana seseorang mencapainya).

\section{Kerangka Penelitian}

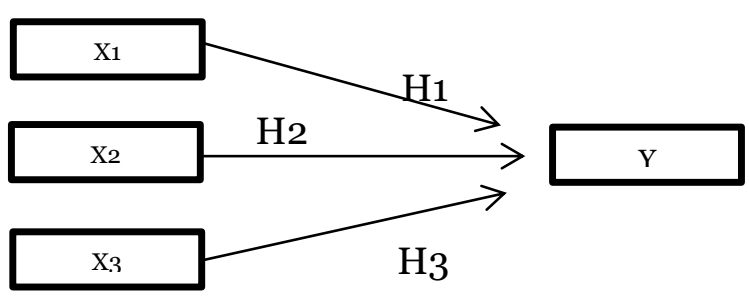

Gambar 1. Kerangka Penelitian

\section{Hipotesis}

H1:Diduga ada pengaruh gaya kepemimpinan terhadap kinerja karyawan Rumah Sakit Taman Harapan Baru.

H2: Diduga ada pengaruh disiplin kerja terhadap kinerja karyawan Rumah Sakit Taman Harapan Baru.

H3: Diduga ada pengaruh gaya kepemimpinan dan disiplin kerja secara simultan terhadap knerja karyawan Rumah Salit Taman Harapan Baru.

\section{METODE PENELITIAN}

Metode penelitian yang digunakan adalah metode penelitian kuantitatif dengan analisis uji validitas, reliabilitas, normalitas, uji T, uji F dan $\mathrm{R}$ square dengan menggunakan SPSS. sampel penelitian untuk populasi 142 orang dengan tingkat kepercayaan 95\% adalah 105 orang pada karyawan Rumah Sakit Taman Harapan Baru.
HASIL PENELITIAN
PEMBAHASAN

Pendidikan terakhir responden dari 105 karyawan Rumah Sakit Taman Harapan Baru pendidikan terakhir SMA/SMK sebanyak 30 karyawan dengan jumlah persentase $28,57 \%$, pendidikan terakhir Diploma 3 (D3) sebanyak 50 karyawan dengan jumlah persentase 47,62\%, pendidikan trakhir Strata 1 (S1) sebanyak 25 karyawan dengan jumlah persentase $23,81 \%$.

Usia responden dari 105 karyawan, yang memiliki umur kurang dari 21 tahun sebanyak 30 karyawan dengan persentase $28,57 \%$, usia 21 - 30 tahun sebanyak 47 karyawan dengan persentase $44,76 \%$, usia 31 - 40 tahun sebanyakk 15 karyawan dengan persentase $14,29 \%$, sedangkan yang memiliki umur lebih dari 40 tahun sebanyak 13 karyawan dengan persentase $12,38 \%$.

Bagian/unit kerja responden dari 105 karyawan Rumah Sakit Taman Harapan Baru yang akan di teliti berada di bagian pendaftaran sebanyak 12 karyawan dengan hasil persentase $11,43 \%$, bagian Rekam medis sebanyak 11 karyawan dengan hasil persentase 10,48\%, bagian poliklinik sebanyak 17 karyawan dengan hasil persentase $16,19 \%$, bagian Laboratorium sebanyak 11 karyawan dengan hasil persentase 10,48\%, bagian administrasi rawat inap sebanyak 11 orang dengan hasil persentase 10,48\%, bagian unit gawat darurat 15 orang dengan hasil persentase $14,29 \%$ bagian administrasi rawat jalan sebanyak 11 orang dengan hasil persentase 9,52\%, dan bagian farmasi sebanyak 18 karyawan dengan presentase $17,14 \%$.

Berdasarkan uji validitas dan reliabilitas dengan menggunakan software 
SPSS diperoleh seluruh item dinyatakan valid dan reliabel.

Uji normalitas dapat diuji dengan cara melihat Normal Probability Plot. Model regresi yang baik adalah data distribusi normal atau mendekati normal, untuk mendeteksi normalitas dan dilakukan dengan melihat penyebaran data (titik) pada sumbu diagonal grafik. Untuk mengetahui data normal atau tidak adalah jika data menyebar di sekitar garis diagonal dan mengikuti arah garis diagonal, maka model regresi memenuhi asumsi normalitas.

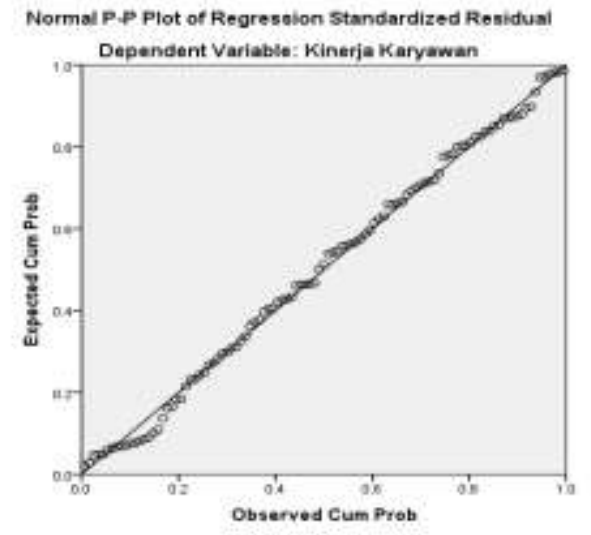

Gambar 1. Uji Normalitas Sumber : Data primer diolah 2020

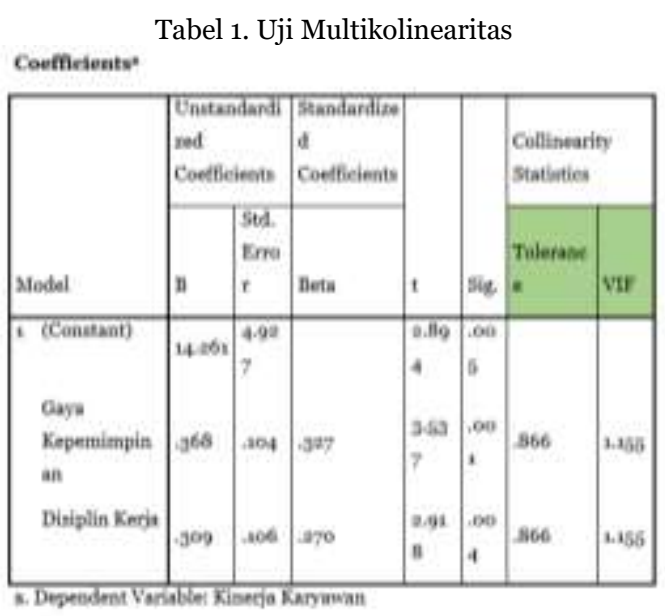

Sumber: Duhe primer yang diolah soas
Dapat disimpulkan bahwa nilai tolerance untuk variabel gaya kepemimpinan (X1) dan disiplin kerja (X2) 0,866 > 0,1 dan nilai VIF 1,155<10, maka variabel-variabel tersebut menunjukkan bahwa tidak terjadi multikolinieritas antara variabel.

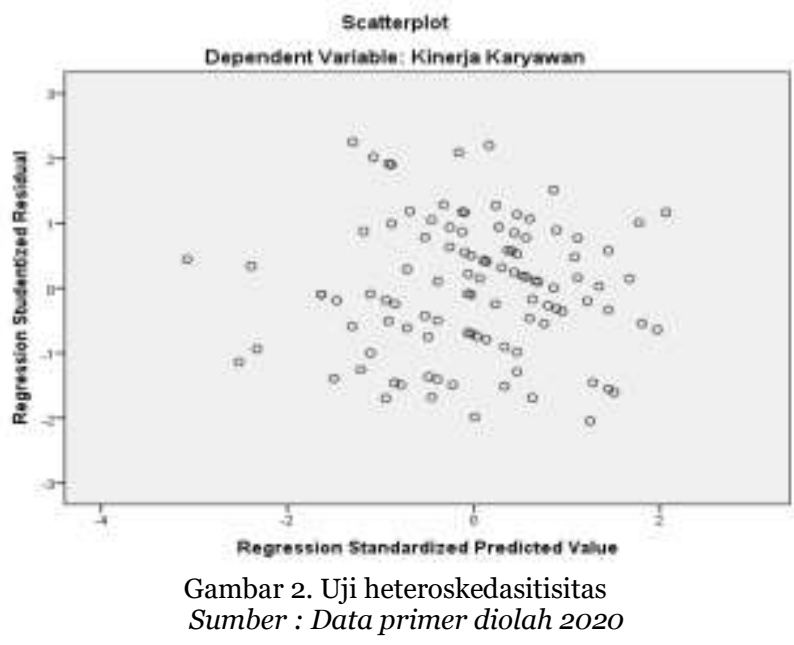

Tidak terdeteksi adanya heteroskedastistas karena titik-titik yang mewakili observasi menyebar di atas dan di bawah angka $\mathrm{O}$ pada sumbu $\mathrm{Y}$ dan penyebaran titik - titik data tidak menyatu dan membentuk pola bergelombang.

\section{Uji T}

Coefficients $^{\mathrm{a}}$

Tabel 2. Uji T

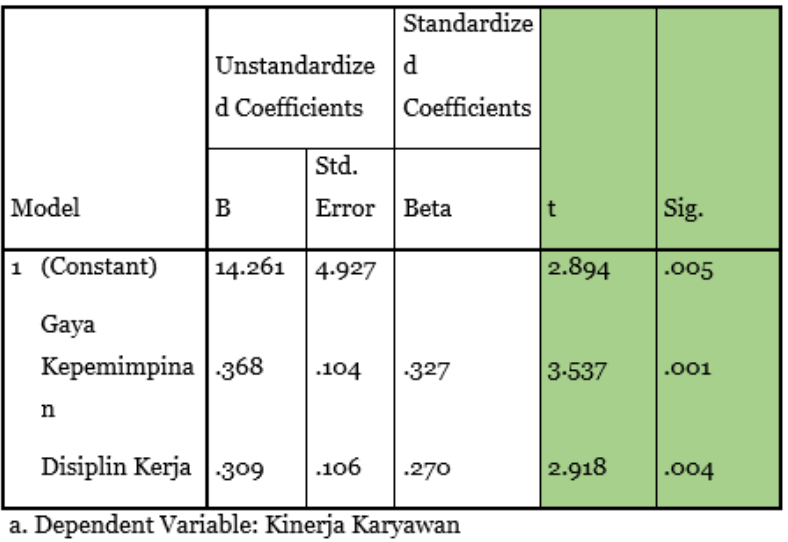

Sumber: Data primer diolah 2020 
Dapat disimpulkan uji t sebagai berikut sebagai berikut :

1. Dari perhitungan berdasarkan tabel di atas, di peroleh nilai t Hitung untuk X1 (Gaya Kepemimpinan) sebesar 3,537 dan nilai $t$ Tabel sebesar 1,98350 , sehingga dapat di artikan bahwa nilai $t$ hitung 3,537 > t tabel 1,98350, berarti Ho di tolak dan Ha diterima. Dengan demikian dapat disimpulkan bahwa variabel gaya kepemimpinan secara parsial mempunyai pengaruh yang signifikan terhadap variabel terikat yaitu kinerja karyawan.

2. Dari perhitungan tabel di atas, diperoleh nilai $t$ Hitung untuk $\mathrm{X} 2$ (Disiplin Kerja) sebesar 2,918 dan nilai t Tabel sebesar 1,98350, sehingga dapat di artikan bahwa nilai thitung 2,918 $>\mathrm{t}$ tabel 1,98350 , berarti Ho di tolak dan Ha di terima. Dengan demikian dapat disimpulkan bahwa variabel bebas (Disiplin kerja) secara parsial mempunyai pengaruh yang signifikan terhadap variabel terikat yaitu kinerja karyawan.

\section{Uji F}

ANOVA $^{\mathrm{a}}$

Tabel 3. Uji Multikolinearitas

\begin{tabular}{|l|l|l|l|l|l|}
\hline Model & $\begin{array}{l}\text { Sum of } \\
\text { Squares }\end{array}$ & df & $\begin{array}{l}\text { Mean } \\
\text { Square }\end{array}$ & F & Sig. \\
\hline $\begin{array}{l}1 \\
\text { Regressio } \\
\mathrm{n}\end{array}$ & 366.918 & 2 & 183.459 & 16.504 & $.000^{\mathrm{b}}$ \\
$\begin{array}{l}\text { Residual } \\
\text { Total }\end{array}$ & 1133.844 & 102 & 11.116 & & \\
\hline
\end{tabular}

a. Dependent Variable: Kinerja Karyawan

b. Predictors: (Constant), Disiplin Kerja, Gaya Kepemimpinan

Sumber: Data primer diolah 2020

Diperoleh nilai $\mathrm{F}$ hitung sebesar 16,504 dengan $\mathrm{F}$ tabel yang didapat berdasarkan $(\mathrm{k} ; \mathrm{n}-\mathrm{k})=(2 ; 105-2)=(2$;
103). Maka didapat $\mathrm{F}$ tabel 3,08, maka $16,504>3,08$. Hal ini menunjukan gaya kepemimpinan dan disiplin kerja secara simultan berpengaruh terhadap kinerja karyawan.

\section{Regresi Linear Berganda}

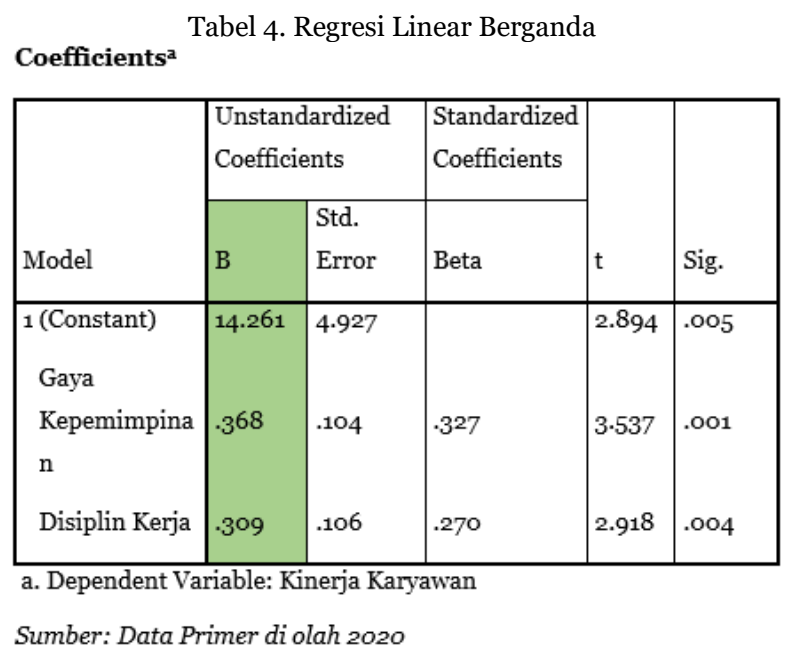

Pengujian regresi linier berganda dapat diketahui persamaan regresi yang diperoleh sebagai berikut: $\mathrm{Y}=14,261+0,368$ $\mathrm{X} 1$ + 0, $309 \mathrm{X} 2$, dimana :

$\mathrm{Y}=$ Variabel terikat (Kinerja Karyawan)

$\mathrm{X} 1$ = Variabel bebas (Gaya Kepemimpinan)

X2 $=$ Variabel bebas (Disiplin Kerja)

$\mathrm{A}=$ Konstanta (nilai $\mathrm{Y}$ 'apabila $\mathrm{X} 1, \mathrm{X} 2, \ldots . \mathrm{Xn}=\mathrm{O}$ )

$\mathrm{B}=$ Koefisien regresi (nilai peningkatan atau penurunan)

Berdasarkan tabel di atas dapat disimpulkan sebagai berikut:

a. Konstanta $=14.261$

Jika variabel gaya kepemimpinan dan disiplin kerja di anggap sama dengan nol, maka variabel kinerja karyawan sebesar 14,261.

b. Koefisien Gaya Kepemimpinan (X1) = 0,368

Jika variabel gaya kepemimpinan mengalami kenaikan, sementara 
didiplin kerja diasumsikan tetap, maka kinerja karyawan akan meningkat sebesar 0,368.

c. Koefisien Disiplin Kerja (X2) = 0,309 Jika variabel disiplin kerja mengalami kenaikan, sementara gaya kepemimpinan di asumsikan tetap, maka kinerja karyawan akan meningkat sebesar 0,309.

\section{Koefisien Determinasi}

\section{Model Summary}

Tabel 5. Koefisien Determinasi

\begin{tabular}{|l|l|l|l|l|}
\hline Model & $\mathrm{R}$ & R Square & $\begin{array}{l}\text { Adjusted R } \\
\text { Square }\end{array}$ & $\begin{array}{l}\text { Std. Error of the } \\
\text { Estimate }\end{array}$ \\
\hline 1 & $.494^{\mathrm{a}}$ & .244 & .230 & 3.33408 \\
\hline
\end{tabular}

a. Predictors: (Constant), Disiplin Kerja, Gaya Kepemimpinan

b. Dependent Variable: Kinerja Karyawan

Sumber : Data primer diolah 2020

Dapat disimpulkan bahwa dalam penelitian ini uji determinasi menggunakan Adjusted $\mathrm{R}$ Square yang menjelaskan apakah penelitian dapat mencari jawaban yang di butuhkan dari populasinya. Kisaran nilai Adjustted R Square adalah o hingga 1, Nilai yang di peroleh sebesar 0,230, artinya sumbangan pengaruh variabel bebas yaitu gaya kepemimpinan dan disiplin kerja terhadap variabel terikat yaitu kinerja karyawan sebesar 0,230 atau sebesar 23,0\%, sisanya 77,0\% di pengaruhi oleh variabel lain yang tidak ada di variabel ini.

\section{Pembahasan}

Berdasarkan dari hasil perhitungan data yang di kemukakan di atas dapat di ketahui bahwa secara parsial dan secara bersama-sama (simultan) terdapat pengaruh terhadap gaya kepemimpinan dan disiplin kerja terhadap kinerja karyawan.

1. Pengaruh gaya kepemimpinan (X1) terhadap kinerja karyawan (Y). Diperoleh nilai t hitung sebesar 3,537 dengan taraf signifikansi sebesar 0,001, taraf signifikansi tersebut $<0,05$. Gaya kepemimpinan tidak berpengaruh terhadap kinerja karyawan Rumah Sakit Taman Harapan Baru. Hal ini dapat di ketahui uji hipotesis secara parsial (uji t) dengan pengujian hipotesis pertama (H1) yaitu gaya kepemimpinan (X1) berpengaruh terhadap kinerja karyawan (Y).

2. Pengaruh Disiplin Kerja (X2) terhadap kinerja karyawan (Y). Di peroleh nilai t hitung sebesar 2,918 dengan taraf signifikansi sebesar 0,004, taraf signifikansi tersebut $<0,05$. Disiplin kerja berpengaruh terhadap kinerja karyawan Rumah Sakit Taman Harpan Baru. Hal ini dapat diketahui uji hipotesis secara parsial (uji t) dengan pengujian hipotesis ke dua (H2) yaitu disiplin kerja (X2) berpengaruh terhadap kinerja karyawan (Y).

3. Pengaruh gaya kepemimpinan (X1) dan disiplin kerja (X2) terhadap kinerja karyawan (Y). Di peroleh nilai f hitung sebesar 16,504 dengan taraf signifikasi sebesar 0,000. Dengan demikian taraf signifikasi < 0,05. Gaya kepemimpinan dan disiplin kerja secara simultan berpengaruh terhadap kinerja Rumah Sakit Taman Harapan Baru. Hal ini dapat di ketahui melalui uji hipotesis secara simultan (uji f) dengan pengujian hipotesis ketiga $\left(\mathrm{H}_{3}\right)$ yaitu gaya kepemimpinan (X1) dan disiplin kerja (X2) berpengaruh terhadap kinerja karyawan (Y). Berarti hasil uji hipotesis dalam penelitian ini menerima $\mathrm{Ha}$ dan menolak Ho. Dengan demikian hipotesis (H3) gaya kepemimpinan dan 
disiplin kerja berpengaruh positif terhadap kinerja karyawan Rumah Sakit Taman Harapan Baru.

\section{KESIMPULAN}

Berdasarkan penelitian dan pembahasan Pengaruh Gaya Kepemimpinan dan Disiplin Kerja terhadap Kinerja karyawan Rumah Sakit Taman Harapan Baru dapat di tarik beberapa kesimpulan yaitu sebagai berikut:

1. Gaya kepemimpinan yang berpengaruh signifikan terhadap kinerja karyawan. hal ini menunjukkan bahwa apabila perusahaan meningkatkan gaya kepemimpinan nya maka semangat kinerja karyawan akan semakin tinggi.

2. Disiplin kerja yang berpengaruh signifikan terhadap kinerja karyawan. semakin tinggi disiplin kerja yang di miliki seseorang maka akan meningkatkan kinerja.

3. Gaya kepemimpinan dan disiplin kerja berpengaruh signifikan terhadap kinerja karyawan . semakin gaya kepemimpinan di terapkan dengan baik di perusahaan begitupun dengan meningkatnya kedisiplinan kerja karyawan akan membuat perusahaan dan karyawan mendapatkan kinerja yang tinggi.

4. Untuk uji determinasi menggunakan nilai Adjustted $R$ Square, nilai yang di peroleh sebesar 0,230, artinya sumbangan pengaruh variabel bebas yaitu gaya kepemimpinan dan disiplin kerja terhadap variabel terikat yaitu kinerja karyawan sebesar 0,230 atau sebesar $23,0 \%$, sisanya 77,0\% di ambil dari luar penelitian ini atau faktor lain yang masih mempengaruhi kinerja karyawan.

\section{Implikasi Manajerial}

Berdasarkan kesimpulan hasil penelitian yang telah disampaikan maka penulis mengemukakan saran-saran sebagai bahan masukan bagi pihak Rumah Sakit Taman Harapan Baru dan penulis selanjutnya memberikan saran-saran sebagai berikut :

1. Bagi Pihak Rumah Sakit Taman Harapan Baru

Perusahaan dalam hal ini harus memperhatikan faktor-faktor yang berkaitan dengan Gaya kepemimpinan. Dengan adanya gaya kepemimpinan maka mampu meningkatkan kinerja karyawan maupun perusahaan, serta perlu adanya pengawasan lebih menyeluruh terhadap disiplin kerja karyawan karena disiplin kerja karyawan tentunya dapat mempengaruhi kinerja karyawan.

2. Penelitian ini di lakukan untuk dapat mengetahui adanya pengaruh gaya kepemimpinan dan disiplin kerja terhadap kinerja karyawan. Mengingat rendahnya pengaruh variebel bebas terhadap variabel terikat di harapkan pihak manajemen mampu memberikan edukasi kepada setiap karyawan bahwa pentingnya gaya kepemimpinan dan disiplin kerja untuk meningkatkan kinerja karyawan. untuk peneliti selanjutnya agar menggunakan variabel lain yang bisa diterapkan di perusahaan ini dalam meneliti hubunganya dengan kinerja karyawan Rumah Sakit Taman Harapan Baru.

\section{Daftar Pustaka}

Azwar, M. S. (2016). Pengaruh gaya kepemimpinan, komunikasi, dan disiplin kerja terhadap kinerja 
karyawan. Jurnal Ilmu dan Riset Manajemen (JIRM), 5(3).

Fauzi, Akhmad dan Rusdi Hidayat Nugroho A. 2020. Manajemen Kinerja, Surabaya: Airlangga University Press.

Jamaludin, A. (2017). Pengaruh Gaya Kepemimpinan Terhadap Kinerja Karyawan Pada PT. Kaho Indahcitra Garment Jakarta. JABE (Journal of Applied Business and Economic), 3(3), 161-169.

Khairizah, A. (2015). Pengaruh Gaya Kepemimpinan Terhadap Kinerja Karyawan (Studi pada Karyawan di Perpustakaan Universitas Brawijaya Malang). Jurnal Administrasi Publik, 3(7), 1268-1272.

Kristanti, Desi dan Lestari Pangastuti. 2019. Kiat-Kiat Merangsang Kinerja Karyawan Bagian Produksi, Surabaya: Media sahabat Cendekia.

Mulyadi, M. (2012). Riset desain dalam metodologi penelitian. Jurnal Studi Komunikasi dan Media, 16(1), 7180.

Musnadi, S., \& Abd Majid, M. S. (2018). Pengaruh motivasi kerja, Lingkungan kerja, Dan budaya organisasi terhadap kinerja karyawan dan dampaknya pada kinerja Bank Aceh Syariah Di Kota Banda Aceh. Jurnal Magister Manajemen, 2(1), 115-122.

Parashakti, R. D., \& Setiawan, D. I. (2019). Gaya Kepemimpinan dan Motivasi terhadap Kinerja Karyawan pada Bank BJB Cabang Tangerang. Jurnal Samudra Ekonomi dan Bisnis, 1O(1).

Pramularso, E. Y. (2017). Pengaruh Disiplin Kerja terhadap Kinerja Karyawan Cipta Hotel Pancoran Jakarta Selatan.

Rahmi, A., \& Aziz, A. (2017). Pengaruh Disiplin Kerja, Pelatihan Kerja dan Kemampuan Kerja Terhadap
Prestasi Kerja Pegawai Biro Umum Kantor Gubernur Provinsi Aceh. Jurnal Bisnis Administrasi, 6(02), 24-31.

Risma, R., Suarni, W. O., \& Arifyanto, A. T. (2020). PENGARUH LAYANAN BIMBINGAN KELOMPOK TERHADAP PENINGKATAN KEDISIPLINAN SISWA. Jurnal Ilmiah Bening (Belajar Bimbingan dan Konseling), 4(1).

Rozalia, N. A. (2015). Pengaruh Motivasi Kerja Dan Disiplin Kerja Terhadap Kinerja Karyawan (Studi Kasus Pada Karyawan PT. Pattindo Malang). Jurnal Administrasi Bisnis, 26(2).

Setiawan, A. (2013). Pengaruh disiplin kerja dan motivasi terhadap kinerjakaryawan pada rumah sakit umum daerah kanjuruhan malang. Jurnal Ilmu Manajemen (JIM), 1(4).

Sinurat, E. (2017). Pengaruh gaya kepemimpinan Terhadap Kepuasan Kerja Karyawan Pada PT. Himawan Putra Medan. Jurnal Ilmiah Methonomi, 3(2), 92-106.

Sunarsi, D. (2018). Pengaruh Gaya Kepemimpinan dan Disiplin Kerja Terhadap Kinerja Karyawan Pada CV. Usaha Mandiri Jakarta. JENIUS (Jurnal Ilmiah Manajemen Sumber Daya Manusia), 1(2).

Syafrina, N. (2017). Pengaruh disiplin kerja terhadap kinerja karyawan pada pt. suka fajar pekanbaru. Eko Dan Bisnis: Riau Economic and Business Review, 8(4), 1-12.

Tyas, R. D., \& Suharyono, B. S. (2018). PENGARUH DISIPLIN KERJA DAN LINGKUNGAN KERJA TERHADAP KINERJA KARYAWAN (Studi Pada Karyawan PT. Pertamina (Persero) Refinery 
Unit IV Cilacap). Jurnal Administrasi Bisnis, 62(1), 172-180.

Zahara, R. N., \& Hidayat, H. (2017). Pengaruh Kepuasan dan Disiplin Kerja Terhadap Kinerja Karyawan Bank di Kota Batam. Journal of Applied Managerial Accounting, 1(2), 150-156. 